\title{
THE UNIVERSITY of EDINBURGH
}

\author{
Edinburgh Research Explorer
}

\section{Controlled hydrothermal growth of vertically-aligned zinc oxide nanowires using silicon and polyimide substrates}

\section{Citation for published version:}

Syed, A, Kalloudis, M, Koutsos, V \& Mastropaolo, E 2015, 'Controlled hydrothermal growth of verticallyaligned zinc oxide nanowires using silicon and polyimide substrates', Microelectronic Engineering, vol. 145, pp. 86-90. https://doi.org/10.1016/j.mee.2015.03.039

\section{Digital Object Identifier (DOI):}

10.1016/j.mee.2015.03.039

Link:

Link to publication record in Edinburgh Research Explorer

Document Version:

Peer reviewed version

Published In:

Microelectronic Engineering

\section{General rights}

Copyright for the publications made accessible via the Edinburgh Research Explorer is retained by the author(s) and / or other copyright owners and it is a condition of accessing these publications that users recognise and abide by the legal requirements associated with these rights.

\section{Take down policy}

The University of Edinburgh has made every reasonable effort to ensure that Edinburgh Research Explorer content complies with UK legislation. If you believe that the public display of this file breaches copyright please contact openaccess@ed.ac.uk providing details, and we will remove access to the work immediately and investigate your claim. 
NOTICE: this is the author's version of a work that was accepted for publication in Microelectronic Engineering. Changes resulting from the publishing process, such as peer review, editing, corrections, structural formatting, and other quality control mechanisms may not be reflected in this document. Changes may have been made to this work since it was submitted for publication. A definitive version was subsequently published in Microelectronic Engineering, [VOL 145, PP. 86-90, (1 September 2015)] DOI: 10.1016/j.mee.2015.03.039

\title{
Controlled hydrothermal growth of vertically-aligned zinc oxide nanowires using silicon and polyimide substrates
}

\author{
Atif Syed*, Michail Kalloudis, Vasileios Koutsos and Enrico Mastropaolo*
}

School of Engineering, The University of Edinburgh, King's Buildings, EH9 3JL, Edinburgh, United Kingdom

*Corresponding authors email: a.syed@ed.ac.uk ; e.mastropaolo@ed.ac.uk

Telephone no.: +44-131-650-5651

Keywords: zinc oxide nanowires, hydrothermal synthesis, Ostwald's ripening, atomic force microscopy.

\begin{abstract}
In this paper, hydrothermal synthesis combined with microfabrication techniques is used for growing vertically-aligned $\mathrm{ZnO}$ nanowires $(\mathrm{NWs})$ on zinc $(\mathrm{Zn})$ seed layers patterned on silicon ( $\mathrm{Si}$ ) and polyimide (PI). The NWs have shown a hexagonal crystalline structure and vertical orientation. The substrate material together with the hydrothermal precursor concentration has shown to influence the diameter and length of the NWs. Atomic force microscopy and scanning electron microscopy have revealed that the substrate material affects the size of the deposited seeds and therefore the morphology of the NWs which show a diameter in the range $100-220 \mathrm{~nm}$ and $130-400 \mathrm{~nm}$ when grown on $\mathrm{Si}$ and PI respectively. NWs grown with an optimised concentration of $2 \mathrm{mM}$ are densely packed and vertically-aligned with a consistent uniform distribution on both types of substrates.
\end{abstract}




\section{Introduction}

In the past few years, zinc oxide $(\mathrm{ZnO})$ nanostructures have been attracting large attention for energy harvesting applications (solar cells [1], nanogenerators [2]) and sensors (gas sensors [3] and biosensors [4]). Till date, various $\mathrm{ZnO}$ nanostructures have been synthesized such as nanorods [5] [6], nanowires [7] [8] [9], nanoplates [10] [11], nanospikes [12], microtubes [13] and nanotubes [14] [15]. In addition, the combination of biocompatibility and piezoelectric properties of $\mathrm{ZnO}$ NWs opens new perspectives for biomedical and chemical sensing [16] [17]. The ability to control morphology, dimensions alignment and position of $\mathrm{ZnO} \mathrm{NWs}$ is crucial for enabling successful and consistent integration into microsystems and for exploiting the NWs' unique properties in innovative transducers and composite materials [18] [19]. For instance, the NWs' diameter plays a key role for the enhancement of their fluorescent properties to be exploited for cancer cells detection [20] [21] [22]. Among the various methods available for growing $\mathrm{ZnO}$ NWs, hydrothermal growth is the most promising due to the inherent low temperature processing particularly suitable for synthesis on polymers and CMOS integration. Nanoimprint lithography, microcontact printing and e-beam lithography have been used to perform patterned growth on seed layers deposited on silicon [23] [24] [25]. However, these techniques are costly, not directly compatible with patterning on flexible polymer-based substrates and with largescale production of semiconductor devices. Photolithography has been used successfully to grow $\mathrm{ZnO}$ nanorods (NRs) on specific patterns onto silicon substrates and on flat flexible substrates (i.e., Kapton) [26] [27]. Although previous works have shown that different seed layer thickness and seed materials have a direct effect on the morphology of $\mathrm{ZnO} \mathrm{NWs}$, additional studies are needed to shed light on the influence of seed layer roughness and of substrate below the seed layer on the NWs' size and morphology [28] [29].

In this paper, hydrothermal synthesis and microfabrication processes have been used to grow $\mathrm{ZnO}$ NWs on precise locations on zinc seed layers patterned on silicon and polymer-on-silicon substrates. The morphology and crystal structure of the NWs grown on the two different substrates and at different precursor concentration has been analysed and compared by using x-ray diffraction, scanning electron microscopy and atomic force microscopy. 


\section{Theory - hydrothermal synthesis}

Hydrothermal synthesis was performed using zinc nitrate hexahydrate $\left(\mathrm{Zn}\left(\mathrm{NO}_{3}\right)_{2} \cdot 6 \mathrm{H}_{2} \mathrm{O}\right)$ and HMTA (hexamethylenetetramine, $\mathrm{C}_{6} \mathrm{H}_{12} \mathrm{~N}_{4}$ ) mixed in equimolar concentration in DI water. Previous studies have shown that HMTA acts as a buffer contributing to the amount of hydroxide ions available for the synthesis (i.e., HMTA decomposes into formaldehyde when heated) [30]:

$\mathrm{C}_{6} \mathrm{H}_{12} \mathrm{~N}_{4}(\mathrm{~s})+10 \mathrm{H}_{2} \mathrm{O}(\mathrm{l}) \rightleftharpoons 6 \mathrm{H}-\mathrm{C}=\mathrm{H}-\mathrm{O}(\mathrm{g})+4 \mathrm{NH}_{4}^{+}(\mathrm{g})+4 O \mathrm{H}^{-}$

$\mathrm{NH}_{3}(g)+\mathrm{H}_{2} \mathrm{O}(l) \rightarrow \mathrm{NH}_{4}(g)+\mathrm{OH}^{-}$

Furthermore, by increasing the $\mathrm{pH}$ of the precursor solution the rate of hydrolysis (formation of $\mathrm{OH}^{-}$ ions) decreases [30]. The $\mathrm{Zn}^{2+}$ ions needed for the formation of the $\mathrm{ZnO}$ nanostructures are produced from zinc nitrate hexahydrate:

$2 \mathrm{OH}^{-}+\mathrm{Zn}^{2+} \rightarrow \mathrm{Zn}(\mathrm{OH})_{2}(\mathrm{~s})$

The resultant hydroxide then reacts with the remaining $\mathrm{Zn}$ ions resulting in $\mathrm{ZnO}$ :

$\mathrm{Zn}(\mathrm{OH})_{2}(\mathrm{~s}) \rightarrow \mathrm{ZnO}(\mathrm{s})+\mathrm{H}_{2} \mathrm{O}$

HMTA is responsible for the formation of $\mathrm{ZnO}$ NWs (reaction described in equation (4)) by restricting the growth of the $\mathrm{ZnO}$ nanostructures only on the $<001>$ facet, hence constraining the growth in one direction. Equation (3) describes the supersaturation stage which is a pre-requisite for the crystallisation of the $\mathrm{ZnO}$ products. By tuning this stage, either by varying time and concentration of the precursor solution, the morphology of $\mathrm{ZnO}$ NWs can be controlled.

\section{Materials and methods}

\subsection{Chemicals}

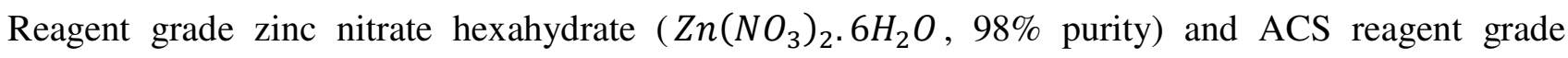
hexamethylenetetramine $\left(\mathrm{C}_{6} \mathrm{H}_{12} N_{4}, 99 \%\right.$ purity) were purchased from Sigma-Aldrich and were used without any further purification. Polyimide (PI-2545) was purchased from HD microsystems. 


\subsection{Microfabrication process}

Figure 1 shows the schematic process flow used to grow $\mathrm{ZnO}$ NWs on patterned $\mathrm{Zn}$ seed layers. Firstly, 3-inch silicon $(\mathrm{Si})$ wafers were cleaned by using acetone, IPA and DI water. The substrates were primed with hexamethyldisilazane (HDMS) while being heated at $60^{\circ} \mathrm{C}$ for $1.5 \mathrm{~min}$ in order to improve the adhesion of the photoresist (PR). $1.5 \mu \mathrm{m}$ of PR (Figure 1(a)) was spin coated using edge bead removal (EBR) thus ensuring that the PR at the edge of the substrate is even. After soft-baking at $90^{\circ} \mathrm{C}$, the substrates were patterned by UV lithography (7 seconds exposure), developed for $1 \mathrm{~min}$, rinsed in DI water and dried with nitrogen gas (Figure 1(b)). Afterwards, an adhesion layer of titanium (Ti) $(10 \mathrm{~nm})$ and zinc $(\mathrm{Zn})$ seed layer $(300 \mathrm{~nm})$ were deposited using e-beam evaporation (Figure 1(c)). At this point, ZnO NWs were grown hydrothermally on the substrates (Figure 1(d)). In particular, the substrates were immersed in the precursor solution containing zinc nitrate hexahydrate and HMTA mixed in equimolar concentration in DI water. Two different concentrations ( $2 \mathrm{mM}$ and $20 \mathrm{mM})$ were used for investigating the influence of precursor concentration on the growth of the $\mathrm{ZnO}$ NWs. The solution was stirred at $550 \mathrm{rpm}$ while monitoring the $\mathrm{pH}$ throughout the process. Stirring was stopped when the $\mathrm{pH}$ reached a saturation point between 6.75-6.85 (5-10 $\mathrm{min})$. Synthesis was carried out for 16-17 hours at $90^{\circ} \mathrm{C}$. Once the hydrothermal process was completed, the substrates were cleaned with DI water and dried in air. Afterwards, lift-off was performed thus removing the NWs grown on the $\mathrm{Zn} / \mathrm{PR} / \mathrm{Si}$ while leaving the NWs grown on the Zn/Si (Figure 1(e)).

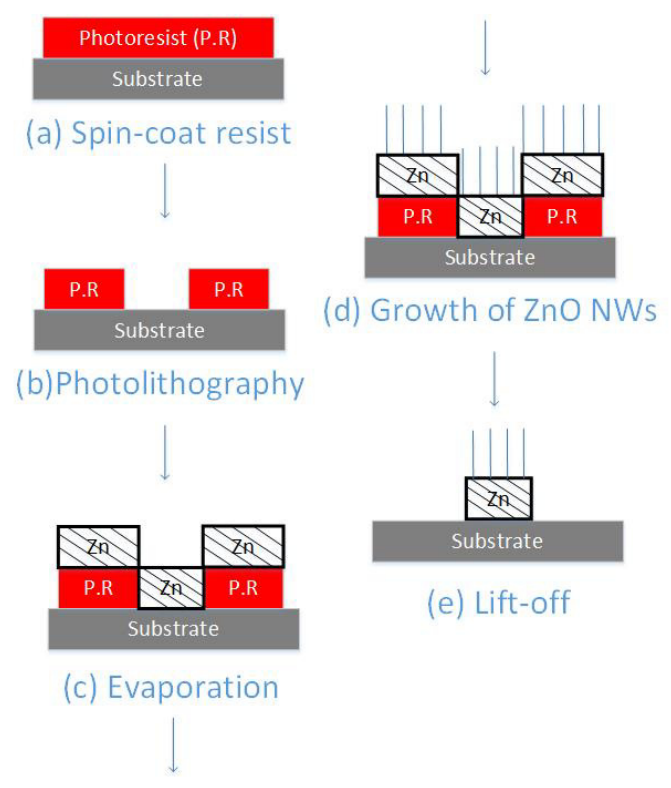

Figure 1: Fabrication process flow. 
In order to investigate the possibility of growing ZnO NWs on polymer films, the process described above was modified to include the deposition of a thin film of PI on top of Si substrates (PI/Si). In this case, before coating the substrates with PR, $1.7 \mu \mathrm{m}$ of PI were spin-coated and cured by increasing the temperature at $4^{\circ} \mathrm{C} / \mathrm{min}$ up to $200^{\circ} \mathrm{C}$ for 1 hour (Figure $1(\mathrm{a})$ ).

\subsection{Measurements}

The crystalline properties of the nanostructures grown on both Si and PI/Si substrates were investigated using x-ray diffraction (XRD) (Bruker D8 Advance in Bragg-Brentano configuration). The morphology and geometry of the nanostructures were investigated using scanning electron microscopy (SEM). Further investigations on the structures morphology were carried out by atomic force microscopy (AFM) (Bruker Multimode 5). AFM scans were performed in tapping mode and using Bruker MPP11100-10 tips (nominal spring constant in the range 20-80 N/m and tip radius of about $12 \mathrm{~nm}$ ).

\section{Results and discussion}

Vertically aligned $\mathrm{ZnO}$ NWs were successfully synthesized on the patterned $\mathrm{Zn}$ seed layers. The synthesis was carried out using two different concentrations ( $2 \mathrm{mM}$ and $20 \mathrm{mM})$ on Si and PI/Si in order to investigate the influence of substrate material and precursor concentration on the diameter of ZnO NWs.

\subsection{Crystal structure}

XRD was performed on the nanostructures grown on $\mathrm{Si}$ and on PI/Si. Figure 2 shows the XRD spectra obtained for $\mathrm{ZnO} \mathrm{NWs}$ grown on bare $\mathrm{Si}$ and on $\mathrm{PI} / \mathrm{Si}$. In both cases, a very sharp peak is observed at 2-theta $=35 \mathrm{deg}$. which is associated to the (002) crystalline orientation thus indicating that the $\mathrm{ZnO}$ NWs are single crystalline and vertically-oriented in the c-direction. The peak observed at 2-theta $~ 36$ deg. is associated to the (002) plane of the Zn seed layer. The much lower amplitudes of the peaks associated to the $\mathrm{Zn}$ seed with respect to the peak associated to the $\mathrm{ZnO}$ NWs indicates that most of the $\mathrm{Zn}$ layer was utilised for the growth. Other peaks associated to the Ti adhesion layer, native oxide, titanium nitride (TiN) and other planes of $\mathrm{ZnO}$ are observed and indicated in Figure 2. The obtained XRD spectra show identical characteristics for NWs grown on $\mathrm{Si}$ and $\mathrm{PI} / \mathrm{Si}$ thus proving that the developed process allows synthesising single crystalline and vertically-oriented $\mathrm{ZnO} \mathrm{NWs}$ regardless the substrate used. 


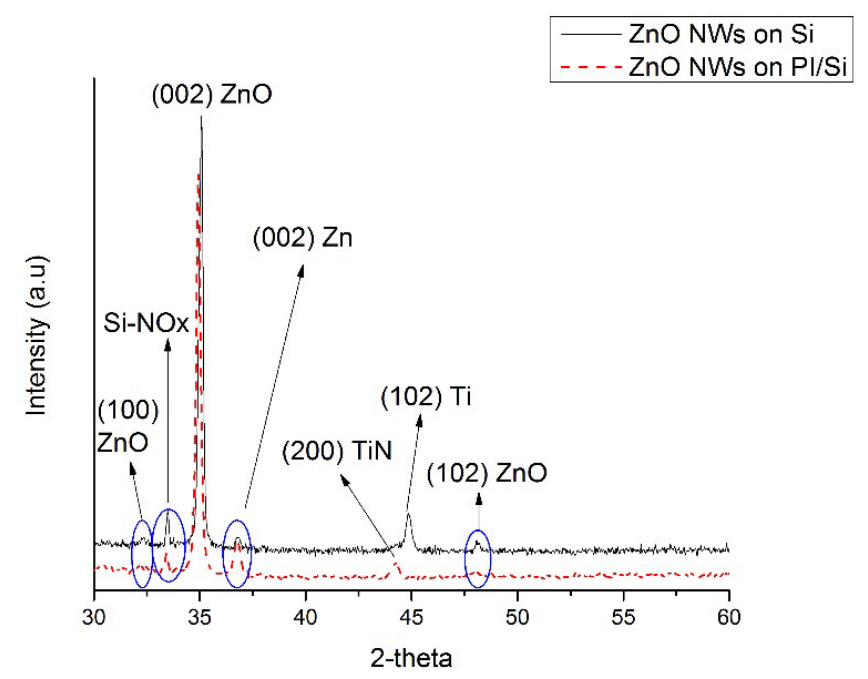

Figure 2: XRD spectra of ZnO NWs grown on Si substrates and PI/Si substrates (Si-NOx: native oxide).

\subsection{Influence of substrate material}

SEM and AFM were used to investigate the height, surface morphologies and diameter of the $\mathrm{ZnO}$ NWs. Figure 3 shows the SEM and AFM micrographs of ZnO NWs grown using $2 \mathrm{mM}$ as precursor concentration on the $\mathrm{Zn}$ seed layer patterned on Si substrates (Figure (a)) and on PI films on $\mathrm{Si}(\mathrm{PI} / \mathrm{Si}$ ) (Figure 3(b)). From Figure 3, it can be seen that the ZnO NWs grown on Si substrates are dense and tightly packed and have more even distribution compared to the ones grown on $\mathrm{Pi} / \mathrm{Si}$ substrates. It is worth pointing out that the NWs are densely distributed and the distinction between a single nanowire and a cluster of nanowires is relatively challenging due to the finite size of the AFM tip apex.

Particle-size distribution analysis was performed in order to estimate accurately the diameter and the diameter distribution of the NWs. When grown on Si substrates, the obtained NWs have a diameter in the range $100 \mathrm{~nm}-220 \mathrm{~nm}$ with average of $130 \mathrm{~nm}$ (SD $40 \mathrm{~nm}$ ) while, when grown on PI/Si, the NW's diameter increased towards higher values in the range $130 \mathrm{~nm}-400 \mathrm{~nm}$ with average of $265 \mathrm{~nm}$ (SD $145 \mathrm{~nm})$. The larger diameter and broader diameter distribution observed when PI/Si substrates were used is most likely due to the intrinsic polymer characteristics of the PI layer under the Zn seed layer. AFM measurements performed on the $\mathrm{Zn}$ seeds after evaporation on Si and on PI/Si revealed RMS roughness values $\sim 31 \mathrm{~nm}$ and $\sim 3 \mathrm{~nm}$, respectively, thus showing an increase of about $27 \%$ in seeds' roughness on the PI/Si substrate. Furthermore, particle-size distribution analysis showed a higher average for grain diameters when depositing the Zn seeds on PI/Si (572 nm, SD $65 \mathrm{~nm}$ ) compared to 
the ones on $\mathrm{Si}(407 \mathrm{~nm}, \mathrm{SD} 96 \mathrm{~nm})$. In addition, it is believed that the surface interactions between the $\mathrm{Zn}$ layer and PI layer are affected by the temperature increase experienced during the hydrothermal process. Under these conditions, a larger amount of $\mathrm{Zn}$ ions are required to initiate the NWs growth from the $\mathrm{Zn}$ seed thus resulting in an increase of the overall NWs diameter.
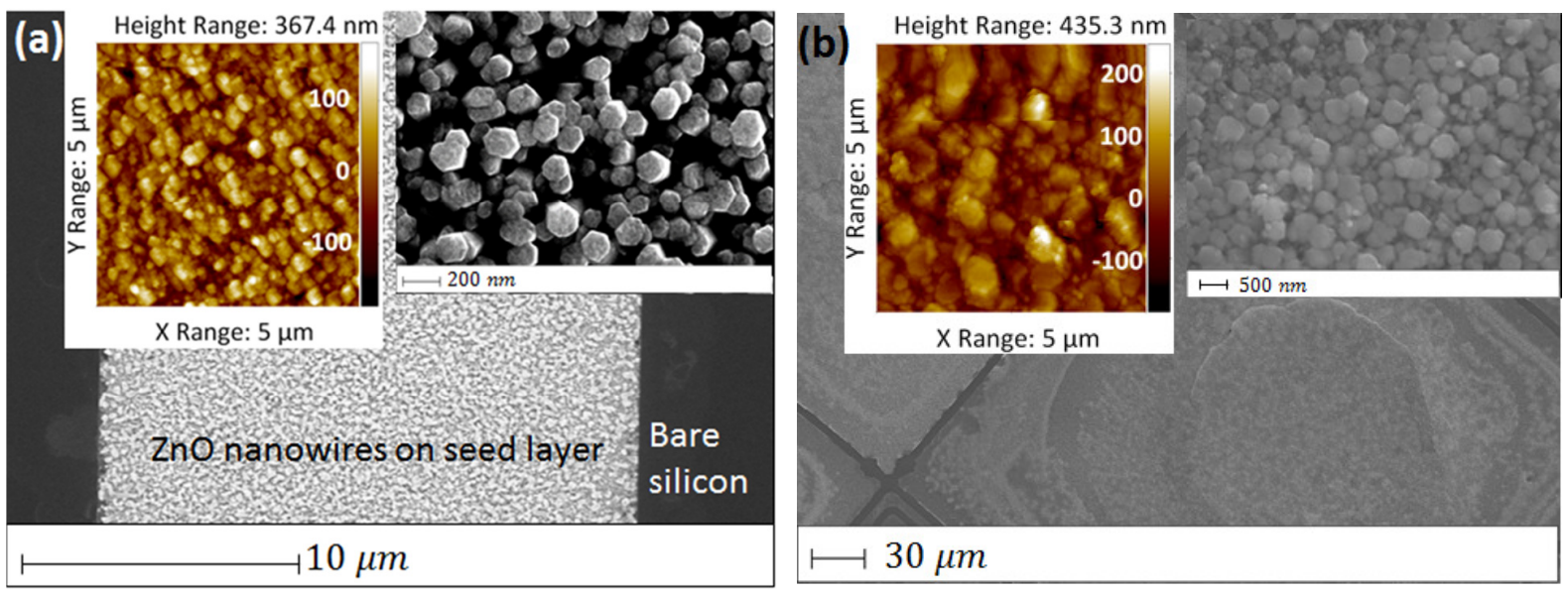

Figure 3: SEM and AFM images of $\mathrm{ZnO}$ NWs grown using $2 \mathrm{mM}$ concentration (a) on $\mathrm{Si}$ and (b) on PI/Si

Figure 4 show the simultaneously acquired phase shift and amplitude images, respectively. The contrast in the phase image is mainly due to topographical effects (single or clustered NWs' edges); otherwise there is no significant contrast thus indicating that the NWs have same chemical composition. The amplitude image emphasises even more the edges of the features (irrespective of their height level) and indicates that the NWs are of similar lateral size. From the AFM analysis, the mean height of $\mathrm{ZnO}$ nanowires grown on Si and PI/Si showed distribution with a kurtosis of 3.275 indicating Gaussian-type distribution and skew of 0.0517 indicating that the size of the NWs is distributed symmetrically with respect to the average value. $\mathrm{ZnO} \mathrm{NWs}$ on PI/Si showed height distribution with a kurtosis of 3.09 and skew 0.31 indicating Gaussian-type distribution but distributed relatively unsymmetrically with respect to the average value.
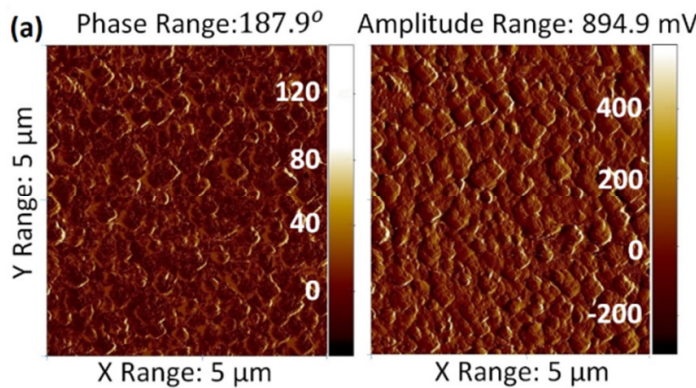

Microelectronic Engineering, Volume 145, 1 September 2015, Pages 86-90, doi:10.1016/j.mee.2015.03.039 


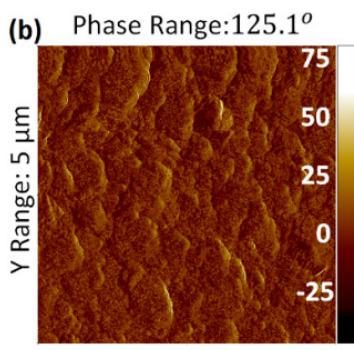

X Range: $5 \mu \mathrm{m}$

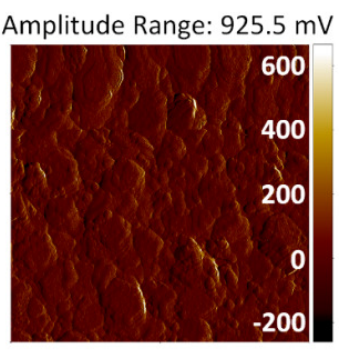

X Range: $5 \mu \mathrm{m}$

Figure 4: AFM phase shift and amplitude image of $\mathrm{ZnO}$ NWs grown using $2 \mathrm{mM}$ precursor concentration on (a) Si and (b) PI/Si substrates.

\subsection{Influence of precursor concentration}

Figure 5 shows the SEM micrographs of $\mathrm{ZnO}$ NWs grown at the precursor concentration of $20 \mathrm{mM}$ on $\mathrm{Si}$ substrates. It is observed that by increasing the concentration by a factor of 10 (from $2 \mathrm{mM}$ to 20 $\mathrm{mM}$ ), the $\mathrm{ZnO} \mathrm{NWs}$ diameter and length increase from about $150 \mathrm{~nm}$ to $1 \mu \mathrm{m}$ and from $1.1 \mu \mathrm{m}$ to $6 \mu \mathrm{m}$, respectively. Table 1 summarises the results obtained in this and other works in literature using similar precursor concentrations [29] [30]. Although, the increase of diameter and length as a function of precursor concentration is in agreement with the other works, the size and the size increase are much larger most likely due to differences in seed layer thickness and seeds diameter. A closer look at Figure 4 shows that Ostwald's ripening occurs when using high precursor concentration. In particular, from the inset of Figure 4, ZnO NWs having small diameter $(\sim 200 \mathrm{~nm})$ can be seen next to thick ZnO NRs with larger diameter $(\sim 1 \mu \mathrm{m})$ due to Ostwald's ripening which is observed in solutions where larger particles (nanostructures) grow at the expense of smaller particles [31]. The unstable molecules at on the surface of the $\mathrm{Zn}$ seed dissolve thus shrinking the size of the seed and therefore the number of free molecules within the solution increases due to the higher precursor concentration. During supersaturation stage (equation (3)), the free molecules deposited close to larger $\mathrm{Zn}$ seeds should dissolve. However, due to the presence of HMTA, which forces the growth in one direction, the free molecules do not dissolve hereby forming $\mathrm{ZnO}$ NWs next to $\mathrm{ZnO}$ NRs. Based on these observations, the growth of thinner NWs arising from Ostwald's ripening can be reduced by increasing synthesis time and/or adjusting HMTA concentration. 


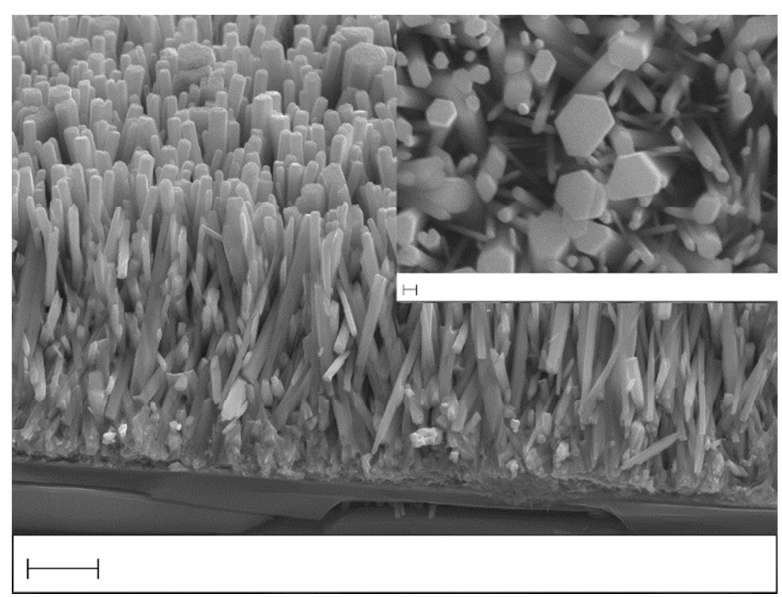

Figure 5: ZnO NRs on Si grown using $20 \mathrm{mM}$ concentration, scale: $2 \mu \mathrm{m}$; (inset scale: $200 \mathrm{~nm}$ ).

\begin{tabular}{|c|c|c|c|c|c|}
\hline & Seed layer & $\begin{array}{c}\text { Seed layer } \\
\text { deposition method }\end{array}$ & $\begin{array}{c}\text { Precursor } \\
\text { concentration }\end{array}$ & $\begin{array}{c}\text { Diameter } \\
\text { (approx.) }\end{array}$ & $\begin{array}{c}\text { Length } \\
\text { (approx.) }\end{array}$ \\
\hline \multirow{2}{*}{ This work } & $\mathrm{Zn}$ & E-beam evaporation & $2 \mathrm{mM}$ & $100-220 \mathrm{~nm}$ & $1.1 \mu \mathrm{m}$ \\
\cline { 4 - 6 } & & & $20 \mathrm{mM}$ & $1 \mu \mathrm{m}$ & $6 \mu \mathrm{m}$ \\
\hline \multirow{2}{*}{ Wang et al. [32] } & $\mathrm{ZnO}$ & \multirow{2}{*}{ RF sputtering } & $8 \mathrm{mM}$ & $40 \mathrm{~nm}$ & $65 \mathrm{~nm}$ \\
\cline { 3 - 6 } & & & $40 \mathrm{mM}$ & $70 \mathrm{~nm}$ & $320 \mathrm{~nm}$ \\
\hline \multirow{2}{*}{ Akgun et al. [33] } & $\mathrm{ZnO}$ & \multirow{2}{*}{ Sol-gel } & $20 \mathrm{mM}$ & $80 \mathrm{~nm}$ & $600 \mathrm{~nm}$ \\
\cline { 3 - 6 } & & & $50 \mathrm{mM}$ & $380 \mathrm{~nm}$ & $800 \mathrm{~nm}$ \\
\hline
\end{tabular}

Table 1: Diameter and length of ZnO NWs grown on silicon substrates.

\section{Conclusions}

Vertically aligned ZnO NWs were grown on patterned Zn seed layers on Si and PI/Si substrates. The process presented allows growing $\mathrm{ZnO}$ NWs on specific locations on the substrates with micrometric accuracy. ZnO NWs grown on both $\mathrm{Si}$ and $\mathrm{PI} / \mathrm{Si}$ substrates showed a clear hexagonal structure with a crystalline orientation in the (002) direction. By controlling the concentration of the precursor solution and also maintaining a constant $\mathrm{pH}$, high quality, tightly packed and vertically aligned $\mathrm{ZnO}$ NWs were synthesized.

The substrate showed to play a key influence on the NWs' morphology. In particular, the measured diameter and diameter distribution of NWs grown on PI/Si was observed to be much larger compared to the case of growth on $\mathrm{Si}$. The larger diameter and diameter range is most likely due larger grain size of the seeds on the polymer substrates (grain diameter and roughness were $28 \%$ and $27 \%$, respectively, 
higher than the ones measured for the seed layers deposited on $\mathrm{Si}$ ). In consistent agreement with other works, the precursor concentration has shown to influence the NWs' diameter. In particular, an approximate 5-fold increase in NWs' diameter was achieved with a 10-fold increase of precursor concentration. Using the combined microfabrication process and chemical synthesis presented in this work, $\mathrm{ZnO} \mathrm{NWs}$ can be grown on different substrates (including polymer substrates) at low temperatures $\left(<100^{\circ} \mathrm{C}\right)$. The presented results give insight on the control and optimisation of $\mathrm{ZnO}$ NWs growth for large-scale fabrication on different substrates with high reproducibility. The method presented can be used to grow ZnO NWs on polydimethylsiloxane (PDMS), Kapton films and other flexible polymers. The ZnO NWs synthesised in this work can be used for application in biomedical sensors, novel transducers, smart materials, nanogenerators and drug delivery systems. 


\section{References}

[1] J.-M. Chui and Y. Tai, "Imrpoving the efficiency of ZnO-based organic solar cell by self-assembled monolayer assisted modulation on the properties of $\mathrm{ZnO}$ acceptor layer," Appl. Mater. Interfaces, vol. 5, pp. 6946-6950, 2013.

[2] Z. L. Wang and J. Song, "Piezoelectric nanogenerators based on zinc oxide nanowire arrays," Science, vol. 312, pp. 242-246, 2006.

[3] L. Wang, Y. Kang, X. Liu, S. Zhang, W. Huang and S. Wang, "ZnO nanorod gas sensor for ethanol detection," Sensors and Actuators B: Chemical, vol. 162, pp. 237-243, 2012.

[4] D. P. Neveling, T. S. van den Heever, W. J. Perold and L. M. Dicks, "A nanoforce ZnO nanowire-array biosensor for the detection and," Sensors and Actuators B: Chemical, vol. 203, pp. 102-110, 2014.

[5] H. Dai, E. W. Wong, Y. Z. Lu and C. M. Lieber, "Synthesis and characterization of carbide nanorods," Nature, vol. 375, pp. 769-772, 1995.

[6] G.-C. Yi, C. Wang and W. I. Park, "Zno nanorods: synthesis, characterization and applications," Semicond. Sci. Technol., vol. 20, p. 2004, S22-S34.

[7] P. Yang, H. Yan, S. Mao, R. Russo, J. Johnson, R. Saykally, N. Morris, J. Pham, R. He and H.-J. Choi, "Controlled growth of ZnO nanowires and their optical properties," Adv. Funct. Mater., vol. 12, pp. 323331, 2002.

[8] M. S. Gudiksen, L. J. Lauhon, J. Wang, D. C. Smith and C. M. Lieber, "Growth of nanowire superlattice structures for nanoscale photonics and electronics," Nature, vol. 415, pp. 670-620, 2002.

[9] D. Banerjee, S. H. Jo and Z. F. Ren, "Enhanced field emission of ZnO nanowires," Adv. Mater., vol. 16, pp. 2028-2032, 2004.

[10] B. Cao and W. Cai, "From ZnO nanorods to nanoplates: Chemical bath deposition growth and surfacerelated emissions," J. Phys. Chem. C, vol. 112, pp. 680-685, 2008.

[11] C. Xu, D. Kim, J. Chun, K. Rho and B. Chon, "Temperature-controlled growth of ZnO nanowires and nanoplates in the temperature range 250-300 degree celcius," J. Phys. Chem. B, vol. 110, pp. 21741-21746, 2006.

[12] D. Pradhan, M. Kumar, Y. Ando and K. T. Leung, "Fabrication of ZnO nanospikes and nanopilars on ITO glass by templateless seed-layer-free electrodeposition and their field-emission properties," ACS Appl. Mater. Inter., vol. 1, pp. 789-796, 2009.

[13] L. Vayssieres, K. Keis, A. Hagfeldt and S.-E. Lindquist, "Three-dimensional array of highly oriented crystalline ZnO microtubes," Chem. Mater., vol. 2001, pp. 4398-4398, 2001. 
[14] L. Yu, G. Zhang, S. Li, Z. Xi and D. Guo, "Fabrication of arrays of Zinc Oxide nanorods and nanotubes in aqueous solution under an external voltage," J. Cryst. Growth, vol. 299, pp. 184-188, 2007.

[15] G. She, X. Zhang, W. Shi, X. Fan and J. C. Chang, "Electrochemical/chemical synthesis of highly-oriented single-crystal $\mathrm{ZnO}$ nanotube arrays on transparent conductive substrates," Electrochem. Commun., vol. 9, pp. 2784-2788, 2009.

[16] Z. Li, R. Yang, M. Yu, F. Bai, C. Li and Z. L. Wang, "Cellular Level Biocompatibility and Biosafety of ZnO Nanowires," J. of Phys. Chem. Lett. C, vol. 112, pp. 20114-20117, 2008.

[17] M. Lee, C.-Y. Chen, S. Wang, S. N. Cha, Y. J. Park, J. M. Kim, L.-J. Chou and Z. L. Wang, "A hybrid piezoelectric structure for wearable nanogenerators," Adv. Mater., vol. 24, pp. 1759-1764, 2012.

[18] M. Riaz, J. Song, O. Nur, Z. L. Wang and M. Willander, "Study of the piezoelectric power generation of ZnO nanowire arrays grown by different methods," Advanced functional materials, vol. 21, pp. 628-633, 2011.

[19] D. Pradhan, F. Niroui and K. T. Leung, "High-Performance, Flexible Enzymatic Glucose Biosensor Based on ZnO Nanowires Supported on a Gold-Coated Polyester Substrate," Appl. Mater. Inter., vol. 2, pp. 24092412, 2010.

[20] H. Hong, J. Shi, Y. Yang, Y. Zhang, J. W. Engle, R. J. Nickles, X. Wang and W. Cai, “Cancer-Targeted Optical Imaging with Fluorescent Zinc Oxide Nanowires," Nano Lett., vol. 11, pp. 3744-3750, 2011.

[21] Q. Rui, K. Komori, Y. Tian, H. Liu, Y. Luo and Y. Sakai, "Electrochemical biosensor for the detection of H2O2 from living cancer cells based on ZnO nanosheets," Analytica Chimica Acta, vol. 670, pp. 57-62, 2010.

[22] O. Lupan, G. Chai, L. Chow, G. A. Emelchenko, H. Heinrich, V. V. Ursaki, A. N. Gruzintsev, I. M. Tiginyanu and A. N. Redkin, "Ultraviolet photoconductive sensor based on single ZnO nanowire," Phys. Status Solidi A, pp. 1-6, 2010.

[23] M.-H. Jung and H. Lee, "Selective patterning of $\mathrm{ZnO}$ nanorods on silicon substrates using nanoimprint lithography," Nanoscale Res. Lett., vol. 6, 2011.

[24] "Simple ZnO Nanowires Patterned Growth by Microcontact Printing for High Performance Field Emission Device," J. Phys. Chem. C, vol. 115, p. 11435, 2011.

[25] S. Xu, Y. Wei, M. Kirkham, J. Liu, W. Mai, D. Davidovic, R. L. Snyder and Z. L. Wang, "Patterned Growth of Vertically Aligned ZnO Nanowire Arrays on Inorganic Substrates at Low Temperature without Catalyst," J. AM. Chem. Soc., vol. 130, p. 14958, 2008.

[26] Y. Tak and K. Yong, "Controlled Growth of Well-Aligned ZnO Nanorod Array Using a Novel Solution Method," J. Phys. Chem. B, vol. 109, p. 19263, 2005.

[27] Y. Qin, R. Yang and Z. L. Wang, "Growth of Horizonatal ZnO Nanowire Arrays on Any Substrate," J. Phys. Chem. C, vol. 112, pp. 18734-18736, 2008.

[28] W.-Y. Wu, C.-C. Yeh and J.-M. Ting, "Effects of Seed Layer Characteristics on the Synthesis of ZnO Nanowires," J. Am. Ceram. Soc., vol. 92, pp. 2718-2723, 2009. 
[29] L.-W. Ji, S.-M. Peng, J.-S. Wu, W.-S. Shih, C.-Z. Wu and I.-T. Tang, "Effect ofseed layer on the growth of wellaligned ZnO nanowires," J. Phys. Chem. Sol., vol. 70, pp. 1359-1362, 2009.

[30] M. Ashfold, R. P. Doherty, N. G. Ndifor-Angwafor and D. J. Riley, "The kinetics of the hydrothermal growth of ZnO nanostructures," Thin Solid Films, vol. 515, pp. 8679-8683, 2007.

[31] J. D. Ng, B. Lorber, J. Witz, A. Théobald-Dietrich, D. Kern and R. Giegé, "The crystallization of biological macromolecules from precipitates: evidence for Ostwald ripening," Journal of Crystal Growth, vol. 168, pp. 50-62, 1996.

[32] S.-F. Wang, T.-Y. Tseng, Y.-R. Wang, C.-Y. Wang, H.-C. Lu and W.-L. Shih, "Effects of Preparation Conditions on the Growth of ZnO Nanorod Arrays Using Aqueous Solution Method," Int. J. Appl. Ceram. Technol., vol. 5, pp. 419-429, 2008.

[33] M. C. Akgun, Y. E. Kalay and H. E. Unalan, "Hydrothermal zinc oxide nanowire growth using zinc acetate dihydrate salt," J. Mater. Res., vol. 27, pp. 1445-1451, 2012.

[34] I. Gonzalez-Valls and M. Lira-Cantu, "Dye sensitized solar cells based on vertically-aligned ZnO nanorods: effect of UV light on power conversion efficiency and lifetime," Energy Environ. Sci., vol. 2, p. 19, 2009. 